\title{
Costs for health care of Holstein cows selected for large versus small body size
}

\author{
J. C. Becker, ${ }^{1}$ B. J. Heins, and L. B. Hansen \\ Department of Animal Science, University of Minnesota, St. Paul 55108
}

\begin{abstract}
The objective of the study was to compare Holstein cows selected for large versus small body size for health care cost. All health treatments were recorded for cows from 1983 to 2005, and treatments were assigned to 1 of 11 categories of health disorders. Actual cost for veterinary treatments, health supplies, and drugs, as well as the value of labor required by animal attendants, was recorded. Data were for 1,035 lactations of 486 cows, of which 199 cows were from the large line and 287 cows were from the small line. Large-line cows had significantly greater total health cost than small-line cows during first lactation and tended to have greater total health cost for the first 3 lactations of cows. During first lactation, large-line cows had a total health cost of $\$ 62.41$, and small-line cows had a total health cost of $\$ 41.41$. Cows in the large line had significantly greater health cost for the individual categories of displaced abomasum and pneumonia than small-line cows during first lactation. Across the first 3 lactations, large-line cows had a total health cost per lactation of $\$ 54.15$ and small-line cows had a total cost of $\$ 38.09$. Cows in the large line had significantly greater health cost for the categories of locomotion and displaced abomasum across the first 3 lactations than small-line cows. Cost for displaced abomasum accounted for most the difference of health cost between the body size lines for both first lactation and for the first 3 lactations of cows.
\end{abstract}

Key words: body size, health cost, type

\section{INTRODUCTION}

North American Holsteins have been selected for increased body size for many years (Tsuruta et al., 2004; VanRaden and Tooker, 2005; VanRaden et al., 2010). Scores for conformation by the Holstein Association USA (Brattleboro, VT) continue to place more favorable ratings on cows with larger body size through the

Received January 13, 2012.

Accepted May 27, 2012.

${ }^{1}$ Corresponding author: beck0740@umn.edu use of body size composite, which is calculated from the 4 linear traits of stature, strength, body depth, and rump width (Holstein Association USA Inc., 2011). Contrary to selection goals of Holstein Association USA Inc., the US Department of Agriculture (USDA) places a negative weight on body size composite within its selection index called lifetime net merit.

Minimizing the health care needs of dairy cows is important from both economic and animal welfare points of view. Diseases such as mastitis, displaced abomasum (DA), ketosis, cystic ovaries, metritis, and lameness severely affect the profitability of dairying through increased veterinary treatments, additional labor, lost milk sales, and involuntary culling (Zwald et al., 2004a). Appuhamy et al. (2009) examined incidence rates of common health disorders of United States Holstein cows and found that first-lactation cows had incidence rates of $5.2 \%$ for ketosis and $4.1 \%$ for DA, whereas multiparous cows had incidence rates of $5.9 \%$ for ketosis and $3.7 \%$ for DA.

Cows with clinical mastitis have decreased milk production and incur treatment cost (Shim et al., 2004), and Ettema and Santos (2004) reported treatment cost of $\$ 50.80$ for each case of clinical mastitis. Jones et al. (1994) analyzed health care costs of a Minnesota experimental herd of Holsteins selected for milk production compared with a 1964 control line of Holsteins. Cows in the milk selection line had higher health care costs during first lactation of $\$ 28.22$, mostly attributed to more cases of mastitis (43\% of total health cost) than the control-line cows.

Furthermore, Mahoney et al. (1986) reported that cows selected to be large had significantly greater health costs than did cows selected to be small. Hansen et al. (1999) reported cows selected to be large were not significantly different from cows selected to be small for production; however, cows selected to be large had shortened productive life and reduced reproductive capabilities than cows selected to be small. The objective of this phenotypic study was to compare health care costs of Holstein cows selected for large versus small body size from the same long-term selection project analyzed by Mahoney et al. (1986) and Hansen et al. (1999). 
MATERIALS AND METHODS

\section{Design of Long-Term Selection Project}

Holstein cows in a long-term selection project at the Northwest Research and Outreach Center, Crookston, of the University of Minnesota were selected for large versus small body size beginning in 1966. During 1966, 60 Holstein cows were paired by sire and were randomly assigned to 1 of 2 groups - large or small-for body size. Cows not fitting into pairs by sire were paired by predicted producing ability for milk production. Progeny were assigned to the same body size line as their dams. Except for service sire selection, both heifers and cows were managed together and identically in a tiestall barn that had relatively large stall sizes and grates over the gutters. The long-term selection project using divergent sire selection continued for more than $40 \mathrm{yr}$.

Throughout the years of the study, service sires were required to be in the top 50\% of bulls for production among the active AI bulls available in the United States at the time of selection. Criteria for selection for production changed over the course of the selection project, and chronologically were (1) milk $(\mathrm{kg}),(2)$ fat $(\mathrm{kg})$ plus protein $(\mathrm{kg})$, and $(3)$ protein $(\mathrm{kg})$. All AI bulls were required to have a reliability of PTA at least $70 \%$ for both production and type traits before 1988, and the reliability requirement was increased to $80 \%$ in 1988.

Other than the minimum culling level for PTA for production, the AI bulls were selected solely based on a body size index $[0.5$ (stature) +0.25 (strength) + 0.25 (body depth)], which was calculated from PTA for stature, strength, and body depth. The 3 most extreme bulls for transmitting large and small body size were selected once each year from the summer genetic evaluations of the USDA for production and from Holstein Association USA Inc. for body size. Selection of an AI bull for 1 yr did not eliminate the bull from consideration for subsequent years. Cows within each body size line were randomly mated to AI bulls, except inbreeding coefficients were not allowed to exceed $6.25 \%$, and calving difficulty was avoided for heifers.

Heifers and cows were periodically added to the herd to expand herd size, especially to facilitate an expansion in the capacity of the tie-stall barn from 60 to 106 stalls in 1987. These additional cows were regarded as new foundation cattle for the selection project for body size and were assigned to 1 of the 2 body size lines. However, cows were required to have at least 3 generations of prescribed large-line or small-line AI bulls beyond the foundation generation to be included in the data for this study.
Data

Cows were born from January 1, 1983 to December 31,1997 , and health care was recorded on an incidence basis from March 28, 1985, to June 17, 2002. Therefore, the data for this study follows, chronologically, the data of Mahoney et al. (1986) and reflects continued divergence for body size of cows in the 2 lines. All cows were required to have calved the first time on or after January 1, 1985.

Eleven categories of health treatment are described in Table 1 . Health treatments were recorded by category, and actual cost for 188 veterinary treatments, health supplies, and drugs were assigned at 2010 values. Also, the amount of labor in minutes required by animal attendants for each health treatment was recorded. Fixed costs for veterinary supplies and drugs were the means from 7 vendors serving Minnesota during the summer of 2010. Costs of veterinary procedures were the means of costs across 3 veterinary clinics in Minnesota. Veterinarian labor was valued at $\$ 115 / \mathrm{h}$, and animal attendant labor was valued at $\$ 10 / \mathrm{h}$. Those health treatments administered routinely to cows in both body size lines, such as vaccinations, deworming, and dry cow therapy, were not included in the data. Health care cost, including the value of labor, was summed for individual categories of health treatment for lactations of cows. Lactation number was coded as first, second, or third, and the lactations of cows beyond third lactation were discarded because these cows were subject to severe culling bias from health problems.

Lactations totaled 1,035 for 486 daughters of 84 AI bulls, and data were for 486 first lactations, 331 second lactations, and 218 third lactations. Cows in the large line were 199 daughters of 45 bulls with 412 lactations $(2.07 / \mathrm{cow})$, and cows in the small line were 287 daughters of 39 bulls with 623 lactations (2.17/ cow). Cows were required to have a recorded BW immediately postpartum to be included in the analysis, and 34 lactations of cows were discarded because BW was missing. Additionally, body dimensions at 1 mo postpartum were recorded for some, but not all, of the 1,035 lactations of 486 cows. The 4 body dimensions were height at withers, length of body, depth of chest, and circumference of chest. Body dimensions were available for 960 of 1,035 lactations (93\%), including 441 of 486 first lactations (91\%) of cows. The BCS of cows was not routinely recorded throughout the years of the study. Over time, the small line grew in cow number relative to the large line, because the cows in the small line remained in the herd longer, calved more frequently, and left more female offspring in the herd (Hansen et al., 1999). 
Table 1. Categories of health care treatment

\begin{tabular}{ll}
\hline Category & Description \\
\hline Mastitis & Clinical mastitis \\
Other udder & Physical injury to teats and udder, edema, treatments not for clinical mastitis \\
Locomotion & Hoof trimming, joint injury, foot rot \\
Displaced abomasum & Displaced abomasum \\
Other digestion & Hardware, upset stomach, off feed, indigestion, bloat \\
Ketosis & Ketosis \\
Milk fever & Milk fever \\
Pneumonia & Pneumonia, labored breathing, coughing, influenza \\
Reproduction & Postcalving reproductive complications up to 40 DIM; retained placenta, cystic ovaries, metritis, prolapse uterus \\
Fertility & Reproductive treatments after 40 DIM; heat synchronization shots, follicular cysts, inducing to calve \\
Other & Kidney or bladder infection, peritonitis, split pelvis, not categorized elsewhere \\
\hline
\end{tabular}

Incidence rates for health treatments were calculated as the number of cows with a treatment for a health category within each body size line divided by the total number of cows in the respective body size line during the lactation. A chi-squared test was used to assess the statistical significance of difference of body size lines for incidence rates during first, second, and third lactations.

Years of calving for all lactations were 1985 to 2002; however, the 20 cows that calved with first lactation during 1985 were pooled for analysis with cows that calved during 1986. Also, 13 cows calved for the second or third time after December 31, 2000, and they were pooled for analysis with cows that calved during 2000. Year-block was then defined as successive 5-yr blocks for year of calving (1986 to 1990, 1991 to 1995, and 1996 to 2000).

Dependent variables for the statistical analysis were health care cost by individual category, as well as summed across all categories, for lactations of cows. Independent variables were the fixed effects of body size line, year-block nested within body size line, lactation number nested within body size line, and the linear, quadratic, and cubic effects of BW at calving nested within body size line as covariables. Additionally, the model fitted cow nested within body size line as a random variable. The BW was regarded as the best descriptor of body size and superior to the individual or combined effects of the 4 recorded body dimensions. Furthermore, BW was recorded for more of the cows than were the body dimensions. The MIXED procedure of SAS (SAS Institute, 2008) was used to obtain solutions and conduct the ANOVA. An alternative fixed effect was a linear covariable for age at calving (mo); however, preliminary analysis revealed this effect did not explain variation $(P>0.05)$ of health care. Effect of sire of cows was not investigated because of the small number of daughters per sire (mean of 5.8 daughters/ sire).

\section{RESULTS AND DISCUSSION}

\section{Response for Body Size}

The means and ranges of observations for BW and the 4 body dimensions (Table 2) indicate a tremendous overlap of phenotypes for the 2 body size lines. Although selected to be large versus small, cows in the 2 body size lines were greatly affected, quite obviously, by environmental and random factors to arrive at realized phenotypic body size. As examples, severe pneumonia as a calf may reduce the eventual body size of a lactating cow and delayed age at first calving may increase the body size of a lactating cow. Therefore, the experimental units in this selection project represent the consequences of long-term selection for or against body size rather than phenotypic classifications for body size without regard to underlying genetics for body size. The previous study of cows in the same selection project from 1969 to 1983 (Mahoney et al., 1986) reported that cows selected for large body size averaged $514 \mathrm{~kg}$ and cows selected for small body size averaged $464 \mathrm{~kg}$ after first calving. In the present study, cows in the large and small lines averaged 615 and 556 $\mathrm{kg}$, respectively, after first calving. Therefore, cows in both body size lines continued to become heavier for BW between the time of the study by Mahoney et al. (1986) and the present study. Cows in the small line were expected to become lighter for BW with time; however, the pervasive selection emphasis for larger body size in the Holstein breed resulted in increased BW of cows in both body size lines in this study. Stated another way, steadfast selection for smaller body size of cows resulted in small-line cows that were divergent from large-line cows for BW; however, small-line cows also became heavier with time.

Cows in the large line had mean BW of $672 \mathrm{~kg}$ immediately after second calving, whereas cows in the small line had mean BW of $595 \mathrm{~kg}$ (Table 2). Cows 


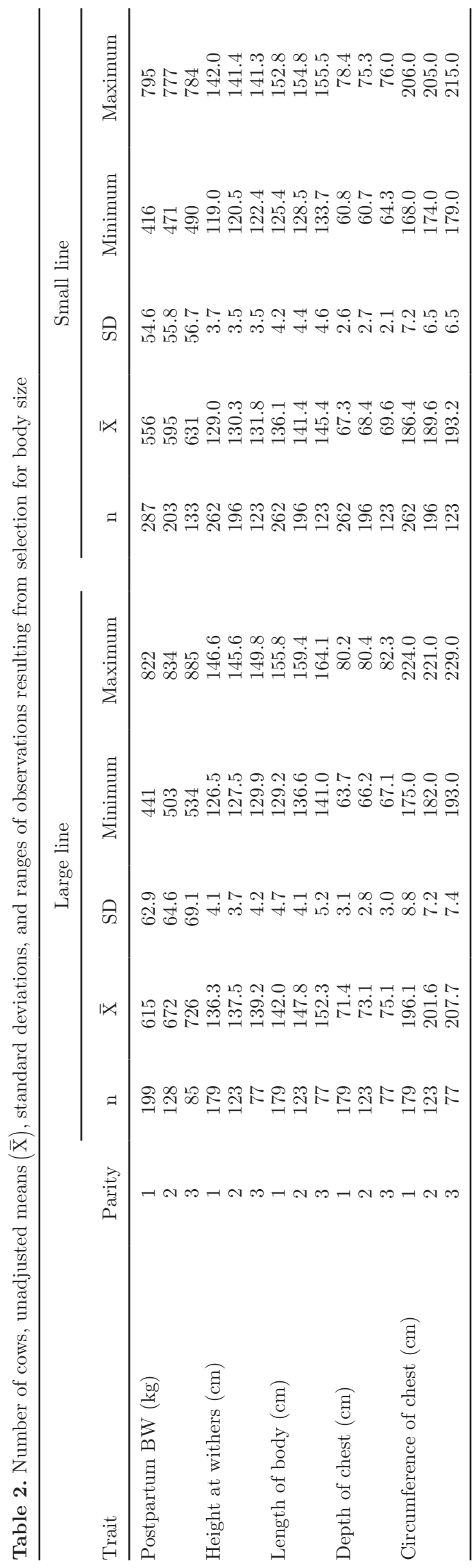

in both body size lines increased in BW from first to second lactation; however, the large-line cows gained more weight from first lactation to second lactation than small-line cows. The BW in third lactation was 726 and $631 \mathrm{~kg}$, respectively, for large-line and smallline cows. Therefore, during third lactation, small-line cows likely would not be regarded as very small cows by most dairy producers. On the other hand, the large-line cows would be regarded as extremely large cows during third lactation by most dairy producers. The large-line cows had greater mean BW at calving of $11 \%$ at first calving, $13 \%$ at second calving, and $15 \%$ for third calving than the small-line cows.

Large-line cows were approximately $7.3 \mathrm{~cm}$ taller than small-line cows at 1 mo postpartum after first, second, and third calving (Table 2). However, for the other 3 body dimensions, large-line cows increased their differences from lactation to lactation in a similar fashion to BW. Phenotypic correlations of BW with the body dimensions across body size lines ranged from 0.65 to 0.72 for height at withers, length of body, and depth of chest within each of the 3 lactations. However, BW had a higher phenotypic correlation with circumference of chest of 0.80 for both first and second lactation and 0.79 for third lactation. Historically, circumference of chest has often been used to approximate BW, and the results from this study of cow size support the substantial positive relationship between these 2 traits. Within the body size lines, all phenotypic correlation of BW with body dimensions were smaller than those across body size lines; however, the strongest correlations (0.61 to 0.75$)$ were once again for BW with circumference of chest.

Although sire selection for the body size lines was based only on production (top 50\% of active AI bulls) and the body size index, the cows in the body size lines were expected to reflect changes for traits genetically correlated with body size. Mean PTA for cows from the April 2012 genetic evaluation of the USDA for the large line and small lines, respectively, were milk $(-660$ $\mathrm{kg},-501 \mathrm{~kg})$, fat $(-21 \mathrm{~kg},-16 \mathrm{~kg})$, protein $(-21 \mathrm{~kg}$, $-17 \mathrm{~kg})$, SCS $(2.91,2.97)$, productive life $(-1.3 \mathrm{mo}$, $+0.6 \mathrm{mo}$ ), and daughter pregnancy rate as a measure of cow fertility $(+0.6 \%,+1.2 \%)$. Differences of mean PTA of the body size lines for production and SCS were small and likely due to chance. However, differences for productive life and cow fertility probably were more meaningful and were likely a consequence of the genetic antagonism of body size with these 2 traits.

\section{Incidence Rates of Health Disorders}

Table 3 has incidence rates for health disorders during first lactation and the large-line cows had a highly 
significant $(P<0.01)$ and greater incidence rate for the categories of other udder disorders (nonmastitis, 5.5 vs. $1.1 \%$ ), DA (14.6 vs. $5.6 \%$ ), and pneumonia (7.0 vs. $1.4 \%$ ) than the small-line cows. Large-line cows also had a significantly $(P<0.05)$ higher incidence rate of treatments for locomotion (41.2 vs. $32.4 \%$ ). Other digestion disorders (9.6 vs. $5.6 \%)$ and the total across categories $(80.4$ vs. $73.2 \%)$ tended $(P<0.10)$ to have higher incidence for large-line cows than small-line cows. For comparison, Appuhamy et al. (2007) found an incidence rate of $7.9 \%$ for DA analyzing health treatments from 2 institutional herds, and Appuhamy et al. (2009) reported an incidence rate of $4.1 \%$ for DA using field data.

During second lactation (Table 4), large-line cows had a highly significant $(P<0.01)$ and greater incidence rate of DA (10.2 vs. $2.5 \%)$ than small-line cows. Large-line cows also had a significantly $(P<0.05)$ higher incidence rate of treatments for other digestion disorders (8.6 vs. 3.5\%). During third lactation (Table $5)$, large-line cows tended to have a significantly $(P<$ $0.10)$ higher incidence rate of treatments for locomotion (34.1 vs. $23.3 \%$ ). Importantly, cows with severe health problems in one lactation may be culled or die before a subsequent lactation. For multiparous cows, Appuhamy et al. (2007) found an incidence rate of $27.0 \%$ for lameness of cows in 2 institutional herds, and Appuhamy et al. (2009) reported an incidence rate of $17.3 \%$ for lameness from field data. Appuhamy et al. (2007) also found an incidence rate of $13.5 \%$ for metabolic diseases for multiparous cows.

\section{Tests of Significance for Fixed Effects}

The $P$-values from the ANOVA for cost of individual health categories and total health cost are in Table 6 .

Table 3. Incidence (\%) of health treatments by category for body size lines during first lactation

\begin{tabular}{lrrr}
\hline & \multicolumn{2}{c}{ Body size } & \\
\cline { 2 - 3 } & $\begin{array}{c}\text { Large } \\
\text { Health category }\end{array}$ & $\begin{array}{c}\text { Small } \\
\text { line }\end{array}$ & \\
\hline Mastitis & 24.6 & 26.3 & -1.7 \\
Other udder disorders & 5.5 & 1.1 & $4.4^{* *}$ \\
Locomotion & 41.2 & 32.4 & $8.8^{*}$ \\
Displaced abomasum & 14.6 & 5.6 & $9.0^{* *}$ \\
Other digestion disorders & 9.6 & 5.6 & $4.0 \dagger$ \\
Ketosis & 6.0 & 5.2 & 0.8 \\
Milk fever & 0.5 & 0.7 & -0.2 \\
Pneumonia & 7.0 & 1.4 & $5.6^{* *}$ \\
Reproduction & 23.6 & 18.5 & 5.1 \\
Fertility & 18.1 & 19.2 & -1.1 \\
Other & 13.1 & 9.1 & 4.0 \\
Total & 80.4 & 73.2 & $7.2 \dagger$ \\
\hline$* * P<0.01 ; * P<0.05 ;+P<0.10$ & & &
\end{tabular}

${ }^{* *} P<0.01 ; * P<0.05 ; \dagger P<0.10$.
Table 4. Incidence (\%) of health treatments by category for body size lines during second lactation

\begin{tabular}{|c|c|c|c|}
\hline \multirow[b]{2}{*}{ Health category } & \multicolumn{2}{|c|}{ Body size } & \multirow[b]{2}{*}{ Difference } \\
\hline & $\begin{array}{l}\text { Large } \\
\text { line }\end{array}$ & $\begin{array}{c}\text { Small } \\
\text { line }\end{array}$ & \\
\hline Mastitis & 21.1 & 27.1 & -6.0 \\
\hline Other udder disorders & 2.3 & 1.5 & 0.8 \\
\hline Locomotion & 24.2 & 20.2 & 4.0 \\
\hline Displaced abomasum & 10.2 & 2.5 & $7.7^{* *}$ \\
\hline Other digestion disorders & 8.6 & 3.5 & $5.1^{*}$ \\
\hline Ketosis & 6.3 & 4.9 & 1.4 \\
\hline Milk fever & 5.5 & 2.5 & 3.0 \\
\hline Pneumonia & 3.1 & 1.0 & 2.1 \\
\hline Reproduction & 10.9 & 14.8 & -3.9 \\
\hline Fertility & 26.6 & 27.1 & -0.5 \\
\hline Other & 5.5 & 3.5 & 2.0 \\
\hline Total & 70.3 & 69.0 & 1.3 \\
\hline
\end{tabular}

${ }^{* *} P<0.01 ;{ }^{*} P<0.05$.

Effect of body size line was highly significant $(P<$ 0.01 ) for other udder disorders (nonmastitis) and locomotion across the first 3 lactations. Body size line was also significant $(P<0.05)$ for DA and approached significance $(P<0.10)$ for total health cost. In each case, the large-line cows had greater health cost than the small-line cows. The effect of lactation number nested within body size line was highly significant $(P<0.01)$ for locomotion, milk fever, and reproduction and was significant $(P<0.05)$ for other udder disorders (nonmastitis). For the other udder disorders (nonmastitis) category, least squares means were highest during first lactation for large-line cows and during second lactation for small-line cows. For locomotion, greatest health cost was during first lactation for both body size lines. For the categories of milk fever and reproduction, cows in third lactation had greatest cost for both body size lines.

Table 5. Incidence (\%) of health treatments by category for body size lines during third lactation

\begin{tabular}{lrcc}
\hline & \multicolumn{2}{c}{ Body size } & \\
\cline { 2 - 3 } & Large & Small & \\
Health category & line & line & Difference \\
\hline Mastitis & 30.6 & 24.8 & 5.8 \\
Other udder disorders & 1.2 & 3.0 & -1.8 \\
Locomotion & 34.1 & 23.3 & $10.8 \dagger$ \\
Displaced abomasum & 8.2 & 6.8 & 1.4 \\
Other digestion disorders & 10.6 & 8.3 & 2.3 \\
Ketosis & 10.6 & 15.0 & -4.4 \\
Milk fever & 16.5 & 18.1 & -1.6 \\
Pneumonia & 2.4 & 3.0 & -0.6 \\
Reproduction & 22.4 & 25.6 & -3.2 \\
Fertility & 32.9 & 31.6 & 1.3 \\
Other & 5.9 & 7.5 & -1.6 \\
Total & 85.9 & 83.5 & 2.4 \\
\hline
\end{tabular}

$\dagger P<0.10$. 
Table 6. $P$-values from tests of significance for cost of individual health categories and total health cost

\begin{tabular}{|c|c|c|c|c|c|c|}
\hline Category & Line & $\begin{array}{c}\text { Lactation no. } \\
\text { within line }\end{array}$ & $\begin{array}{l}\text { Year block } \\
\text { within line }\end{array}$ & $\begin{array}{c}\text { BW } \\
\text { within line }\end{array}$ & $\begin{array}{c}\mathrm{BW}^{2} \\
\text { within line }\end{array}$ & $\begin{array}{c}\mathrm{BW}^{3} \\
\text { within line }\end{array}$ \\
\hline df & 1 & 4 & 4 & 2 & 2 & 2 \\
\hline Mastitis & 0.41 & 0.62 & $<0.01^{* *}$ & 0.55 & 0.58 & 0.60 \\
\hline Locomotion & $<0.01^{* *}$ & $<0.01^{* *}$ & $<0.01^{* *}$ & $<0.01^{* *}$ & $<0.01^{* *}$ & $<0.01^{* *}$ \\
\hline Displaced abomasum & $0.03^{*}$ & 0.48 & 0.60 & $<0.01^{* *}$ & $<0.01^{* *}$ & $<0.01^{* *}$ \\
\hline Other digestion disorders & 0.22 & 0.71 & 0.39 & 0.45 & 0.47 & 0.49 \\
\hline Pneumonia & 0.63 & 0.46 & $<0.01^{* *}$ & 0.62 & 0.64 & 0.67 \\
\hline Reproduction & 0.98 & $<0.01^{* *}$ & 0.12 & 0.99 & 0.99 & 0.99 \\
\hline Fertility & 0.96 & 0.20 & 0.23 & 0.55 & 0.53 & 0.53 \\
\hline Other & 0.38 & 0.87 & 0.27 & 0.66 & 0.66 & 0.66 \\
\hline Total & $0.07 \dagger$ & 0.13 & $<0.01^{* *}$ & $0.02 *$ & $0.02^{*}$ & $0.01 *$ \\
\hline
\end{tabular}

${ }^{* *} P<0.01 ;{ }^{*} P<0.05 ; \dagger P<0.10$.

Effect of year-block nested within body size line was highly significant $(P<0.01)$ for mastitis, other udder disorders (nonmastitis), locomotion, ketosis, pneumonia, and total health cost. The linear, quadratic, and cubic effects of BW nested within body size line were significant $(P<0.05)$ for only the categories of other udder disorders (nonmastitis), locomotion, and DA, as well as for total health cost. For all regression coefficients that were statistically significant, the linear coefficient was positive, the quadratic coefficient was negative, and the cubic coefficient was again positive.

\section{Health Cost During First Lactation}

Results for only first lactations from the multilactation analysis are reported separately, because results from later lactations are likely biased due to culling or death of cows with the most severe health problems. Least squares means for total health cost for first lactation were $\$ 62.41$ and $\$ 41.41$, respectively, for large-line and small-line cows (Table 7), and the difference was highly significant $(P<0.01)$. Therefore, health care costs were $34 \%$ higher (difference of $\$ 21.00$ divided by the mean for the large line) for large-line cows than small-line cows. The previous study from this selection project by Mahoney et al. (1986) with cows from 1969 to 1983 found the large-line cows had almost twice the health cost ( $\$ 12.10$ vs. $\$ 6.57$ ) of small-line cows during first lactation. When the 1984 health costs were adjusted for inflation to 2010 health costs (US Bureau of Labor Statistics, 2011), cows in the study of Mahoney et al. (1986) had a health cost of $\$ 25.39$ and $\$ 13.79$ for large-line and small-line cows, respectively. Therefore, the health costs increased dramatically for both body size lines of cows from the previous study (data from 1969 to 1983 ) to the present study (data from 1985 to 2002). However, the health care cost during first lactation in this study was less than that found by Jones et al. (1994) for a milk selection line compared with a 1964 control line of Holsteins (\$97.65 vs. $\$ 59.14$, re-

Table 7. Least squares means and percentage of total health costs by category for body size lines during first lactation

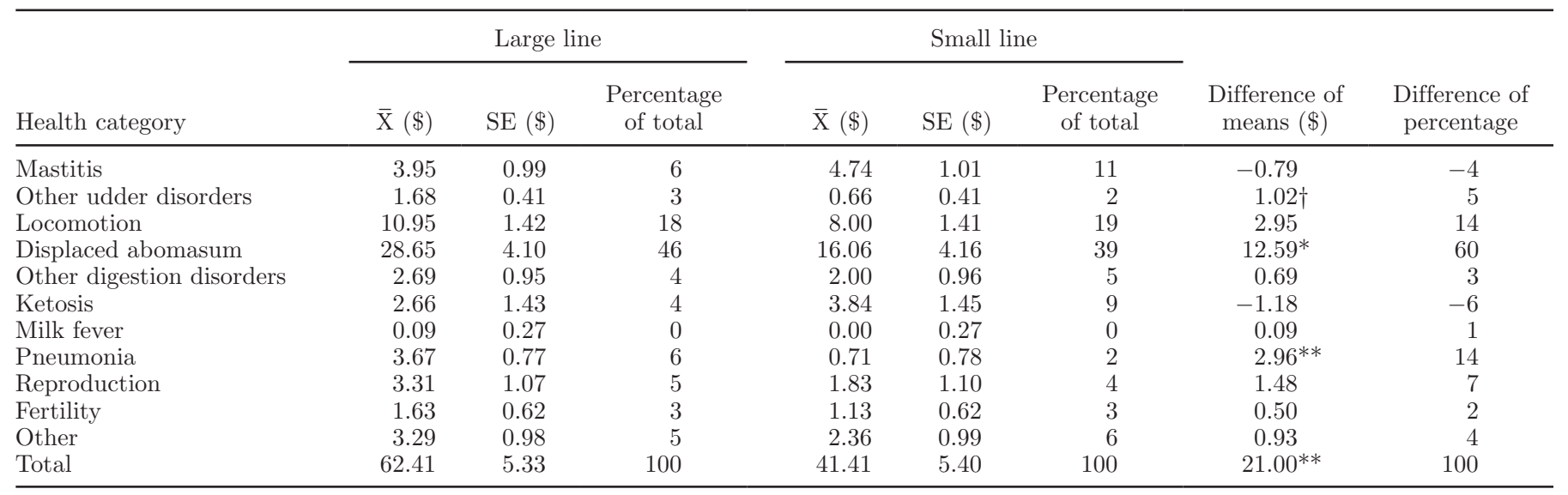

${ }^{* *} P<0.01 ;{ }^{*} P<0.05 ; \dagger P<0.10$. 
Table 8. Least squares means and percentage of total health costs by category for body size lines across lactations

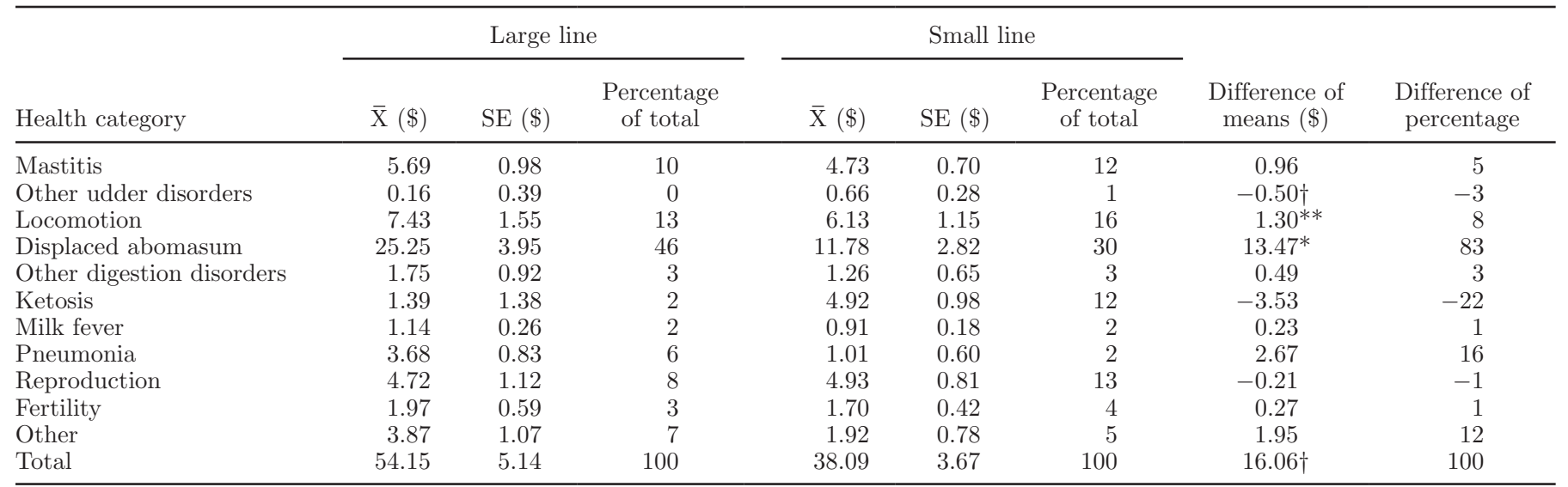

${ }^{* *} P<0.01 ;{ }^{*} P<0.05 ; \dagger P<0.10$.

spectively) when costs were adjusted for inflation (US Bureau of Labor Statistics, 2011). However, the health care cost during first lactation in the present study was less than that of Zwald et al. (2004b), who reported that the cost of health problems during first lactation ranged from $\$ 128$ to $\$ 169$.

Table 7 also has least squares means of health care cost for individual categories during first lactation for the body size lines. Much of the difference between body size lines $(60 \%)$ was because of the significant $(P<0.05)$ difference for DA. However, the pneumonia category also contributed significantly $(P<0.01)$ to the difference for health cost of large-line and small-line cows. Furthermore, the cost for other udder disorders (nonmastitis) treatments tended $(P<0.10)$ to be greater for the large-line cows than small-line cows. However, the health cost for other udder disorders (nonmastitis) was considerably less than the health cost of mastitis, which did not differ significantly for the body size lines. Just 3 of the categories - other udder disorders (nonmastitis), DA, and pneumonia-accounted for $79 \%$ of the difference of total cost for health care between the large-line and small-line cows during first lactation.

The line difference for DA may potentially be attributed to the large-line cows having larger calves (2.5 $\mathrm{kg}$ heavier; Hansen et al., 1999), larger body cavities and, consequently, a greater internal void after calves were born compared with small-line cows, and these differences may have, in turn, predisposed the large-line cows to DA (Hansen et al., 1999). Zwald et al. (2004b) reported correlations between PTA for probability of disease occurrence and PTA for type traits, and found the correlation of occurrence of DA with stature was 0.08 , with strength was 0.11 , and with body depth was 0.11 .

Treatment cost for pneumonia was more than 5 times greater $(P<0.01)$ for the large-line cows than the small-line cows during first lactation. Lyons et al. (1991) reported that cows with incidence of pneumonia treatment had a genetic correlation of 0.76 with digestion incidence and a correlation of 0.52 with mammary incidence. These genetic correlations suggest that cows that have one type of health problem are predisposed to another type of health problem.

\section{Health Costs for the First 3 Lactations}

Analyzing health cost for successive lactations of cows within the same statistical model may result in biased solutions, especially for later lactations, because cows with extreme health care costs were more likely to have been culled or die on the farm before subsequent lactations. The use of a mixed model with cow as a

Table 9. Least squares means of total health cost $(\$)$ for body size lines by lactation number

\begin{tabular}{|c|c|c|c|c|c|}
\hline \multirow[b]{2}{*}{ Parity } & \multicolumn{2}{|c|}{ Large line } & \multicolumn{2}{|c|}{ Small line } & \multirow{2}{*}{$\begin{array}{c}\text { Difference } \\
\text { of means }\end{array}$} \\
\hline & $\overline{\mathrm{X}}$ & SE & $\overline{\mathrm{X}}$ & SE & \\
\hline 1 & 62.41 & 5.33 & 41.41 & 5.40 & $21.00^{* *}$ \\
\hline 2 & 50.85 & 7.52 & 28.33 & 5.64 & $22.52^{*}$ \\
\hline 3 & 49.20 & 10.22 & 44.54 & 6.71 & 4.66 \\
\hline
\end{tabular}


Table 10. Least squares means of total health cost $(\$)$ for body size lines by year block

\begin{tabular}{lcccccc}
\hline & \multicolumn{2}{c}{ Large line } & & \multicolumn{2}{c}{ Small line } & \\
\cline { 2 - 3 } Year block & $\overline{\mathrm{X}}$ & $\mathrm{SE}$ & & $\overline{\mathrm{X}}$ & $\mathrm{SE}$ & $\begin{array}{c}\text { Difference } \\
\text { of means }\end{array}$ \\
\hline $1986-1990$ & 35.58 & 6.79 & & 29.89 & 5.72 & 5.69 \\
$1991-1995$ & 60.24 & 7.17 & & 41.59 & 5.43 & $18.65^{*}$ \\
$1996-2000$ & 66.64 & 7.94 & & 42.79 & 5.52 & $23.85^{*}$ \\
\hline$* P<0.05$ & & &
\end{tabular}

random variable may account for some, but perhaps not all, of this culling bias.

Across the first 3 lactations of cows, the body size lines tended to differ significantly $(P<0.10)$ for health care cost (Table 8$)$. Least squares means for total cost of health care across lactations were $\$ 54.15$ and $\$ 38.09$, respectively, for the large-line and small-line cows, and the health costs were $30 \%$ higher (difference of $\$ 16.06$ divided by the mean for the large line) for large-line cows than the small-line cows. The previous report (Mahoney et al., 1986) of health care costs from this long-term selection project found cows selected for large body size had significantly $(P<0.01)$ greater health cost ( $\$ 12.82$ vs. $\$ 8.39$ ) across lactations than cows selected for small body size. Adjusted for inflation (US Bureau of Labor Statistics, 2011), the cows selected for large and small body size had health care costs of $\$ 26.91$ and $\$ 17.61$, respectively; therefore; the health costs increased substantially for both body size lines since the previous study (Mahoney et al., 1986).

Most of the difference (83\%) of total health cost for the body size lines across the lactations was because of the significant $(P<0.05)$ difference for DA. Zwald et al. (2004b) reported an antagonistic relationship of stature, strength, and body depth with metabolic disorders such as DA.

Locomotion $(8 \%)$ contributed significantly $(P<0.01)$ to the difference for total health cost across the lactations. The feet and legs of large-line cows supported more BW than did the feet and legs of small-line cows; consequently, the large-line cows would be expected to have feet and legs that were more prone to injury than the small-line cows. Furthermore, Hansen et al. (1999) reported the large-line cows in this selection project had mean withers height of $139 \mathrm{~cm}$ during third lactation compared with $131 \mathrm{~cm}$ for small-line cows. The higher center of gravity of large-line cows compared with small-line cows may have caused the large-line cows to be more prone to slipping and falling, which could affect locomotion.

Least squares means of total health cost by lactation number are in Table 9. Health care costs decreased for both large-line and small-line cows from first lactation to second lactation, but then increased during third lactation for small-line cows. Consequently, the difference for health care cost was highly significant $(P<$ $0.01)$ during first lactation and significant $(P<0.05)$ during second lactation for large-line cows compared with small-line cows. However, the body size lines did not differ for health care cost during third lactation.

Table 10 has least squares means of total health cost for the 3-yr blocks. The difference of body sizes line for total health cost was $\$ 5.69$ for the first-year block, and the difference increased to $\$ 18.65$ and $\$ 23.85$ during second- and third-year blocks, respectively. From first- to second-year block, the large line increased $41 \%$, whereas the small line increased $28 \%$, for total health cost. Apparently, the continued divergence of BW for the body size lines with time (across year blocks) resulted in a corresponding increase in health care cost.

\section{CONCLUSIONS}

Greater cost for health care was incurred for cows selected for large compared with small body size in this study. The difference of the body size lines for total health cost was mostly attributed to an increase in cost of treatment for DA, with $60 \%$ of differences of health costs during first lactation and $83 \%$ of differences across the first 3 lactations due to DA. This is in agreement with a previous study of health care costs from an earlier period of time for cows in this selection project (Mahoney et al., 1986). Consequently, the Holstein cows in the large line were economically disadvantaged compared with those in the small line for health care cost, which is an important contributor to profitability of dairying. Cows that require less health care are also preferable from an animal welfare point of view. Continued selection for larger body size of cows may not be justifiable.

\section{REFERENCES}

Appuhamy, J. A. D. R. N., B. G. Cassell, and J. B. Cole. 2009. Phenotypic and genetic relationships of common health disorders with milk and fat yield persistencies from producer-recorded health data and test-day yields. J. Dairy Sci. 92:1785-1795.

Appuhamy, J. A. D. R. N., B. G. Cassell, C. D. Dechow, and J. B. Cole. 2007. Phenotypic relationships of common health disorders 
in dairy cows to lactation persistency estimated from daily milk weights. J. Dairy Sci. 90:4424-4434.

Ettema, J. F., and J. E. P. Santos. 2004. Impact of age at calving on lactation, reproduction, health, and income in first-parity Holsteins on commercial farms. J. Dairy Sci. 87:2730-2742.

Hansen, L. B., J. B. Cole, G. D. Marx, and A. J. Seykora. 1999. Productive life and reasons for disposal of Holstein cows selected for large versus small body size. J. Dairy Sci. 82:795-801.

Holstein Association USA Inc. 2011. Holstein type-production sire summaries. Holstein Association USA Inc., Brattleboro, VT.

Jones, W. P., L. B. Hansen, and H. Chester-Jones. 1994. Response of health care to selection for milk yield of dairy cattle. J. Dairy Sci. $77: 3137-3152$.

Lyons, D. T., A. E. Freeman, and A. L. Kuck. 1991. Genetics of health traits in Holstein cattle. J. Dairy Sci. 74:1092-1100.

Mahoney, C. B., L. B. Hansen, C. W. Young, G. D. Marx, and J. K. Reneau. 1986. Health care of Holsteins selected for large or small body size. J. Dairy Sci. 69:3131-3139.

SAS Institute. 2008. SAS/STAT Software. Release 9.2. SAS Institute Inc., Cary, NC.

Shim, E. H., R. D. Shanks, and D. E. Morin. 2004. Milk loss and treatment costs associated with two treatment protocols for clinical mastitis in dairy cows. J. Dairy Sci. 87:2702-2708.
Tsuruta, S., I. Misztal, and T. J. Lawlor. 2004. Genetic correlations among production, body size, udder, and productive life traits over time in Holsteins. J. Dairy Sci. 87:1457-1468.

US Bureau of Labor Statistics. 2011. Inflation calculator. Accessed Feb. 16, 2012. http://www.bls.gov/data/inflation_calculator.htm. VanRaden, P. M., J. B. Cole, M. E. Tooker, and T. A. Cooper. 2010 Genetic base changes for January 2010. Accessed Aug. 15, 2011. http://aipl.arsusda.gov/reference/base2010.htm.

VanRaden, P. M., and M. E. Tooker. 2005. Genetic base changes for February 2005. Accessed Aug. 15, 2011. http://aipl.arsusda.gov/ reference/arch/base2005.htm.

Zwald, N. R., K. A. Weigel, Y. M. Chang, R. D. Welper, and J. S. Clay. 2004a. Genetic selection for health traits using producerrecorded data. I. Incidence rates, heritability estimates, and sire breeding values. J. Dairy Sci. 87:4287-4294.

Zwald, N. R., K. A. Weigel, Y. M. Chang, R. D. Welper, and J. S. Clay. 2004b. Genetic selection for health traits using producerrecorded data. II. Genetic correlations, disease probabilities, and relationships with existing traits. J. Dairy Sci. 87:4295-4302. 